\title{
Exercise Frequency, High Activation Positive Affect, and Psychological Well-Being: Beyond Age, Gender, and Occupation
}

\author{
Danilo Garcia $^{1 *}$, Trevor Archer ${ }^{2}$, Saleh Moradi ${ }^{2}$, Ann-Christine Andersson-Arntén ${ }^{2}$ \\ ${ }^{1}$ Institute of Neuroscience and Physiology, Psychiatry and Neurochemistry, Forensic Psychiatry, \\ The Sahlgrenska Academy, University of Gothenburg, Gothenburg, Sweden \\ ${ }^{2}$ Department of Psychology, University of Gothenburg, Gothenburg, Sweden \\ Email: *danilo.garcia@euromail.se
}

Received January $25^{\text {th }}, 2012$; revised February $17^{\text {th }}, 2012$; accepted March $21^{\text {st }}, 2012$

\begin{abstract}
Regular physical exercise contributes to marked reductions in psychosocial stress, the enhancing of positive affect and well-being. However, affect can be measured as high (e.g., engaged) or low (e.g., content) activation affect. To ascertain further these interactions, we examined the relationship between exercise frequency (i.e., how often an individual engages in physical activities) and affect and Psychological Well-Being (PWB). We investigate this relationship in the context of individuals' gender, age, psychosomatic symptoms (i.e., headaches, pain in shoulders, neck or other parts of the body), sleeping problems, smoking habits, and Body Mass Index (BMI). Moreover, we also investigate if the relationship between exercise frequency and affect differs depending on the dimension of affect (low or high activation). In Study $1(N=635), 2(N=311)$, and $3(N=135)$ high activation positive affect (PA) predicted frequently exercising, while high activation negative affect (NA) predicted being less physically active. Moreover, high activation PA was negatively related to smoking habits and to how often the participant had sleeping problems. Finally, the relationship between frequently exercising and high activation affect was still present when controlling for age, occupation and gender. Moreover, in Study 2, high activation PA remained strongly related to exercise frequency even when we controlled for BMI. In Study 3, frequent physical activity was also related to PWB. In Study 4, participants $(N=150)$ self-reported low activation affect. All findings in regard to exercise frequency were replicated, with the exception of the relationship to affect. Psychological resources (i.e., PWB), the frequent experience of PA, together with the infrequent experience of NA may provide for the facilitation of an exercise regime and healthy behavior. Thus, regular physical exercise remains as a health-ensuring necessity over age, gender, and occupation. Nevertheless, high activation positive affect should be in focus.
\end{abstract}

Keywords: Affect; BMI; Exercise; Health; Negative Affect; Positive Affect; Sleeping Problems; Smoking; Psychosomatic Symptoms

\section{Introduction}

Regular physical exercise has been described as a planned, structured physical activity which fulfills the purpose of improving one or more aspects of physical fitness and functional capacity (Morris \& Schoo, 2004), encompassing bodily activeties that enhance/maintain physical fitness, with frequent and regular exercise boosting the immune system (Kurth, Moore, Gaziano, Kase, Stampfer, Berger, \& Buring, 2006). The regularity of physical exercise is, for instance, associated to individuals who experience high positive affect (PA) and low negative affect (NA; Norlander, Bood, \& Archer, 2002). In turn, frequently exercising is associated with mental health, facilitating the prevention of depression and anxiety, as well as the promotion and maintenance of positive self-esteem in both adolescents (Rees \& Sabia, 2010; Rothon, Edwards, Bhui, Viner, Taylor, \& Stansfeld, 2010) and adults (Annesi, 2010; Arciero \& Ormsbee, 2009; Baldwin, 2010). In this regard, the links between exercise and affect seem to be modulated by individuals' propensity to perform regular physical exercise (Sjögren, Nissinen, Järvenpää, Ojanen, Vanharanta, \& Mälkiä, 2006; Von Thiele Schwarz, Lindfors, \& Lundberg, 2008).

*Corresponding author.
Indeed, the role of affective personality attributes has offered insights pertaining to health and well-being among varying populations, both healthy and clinical (Andersson-Arntén, Jansson, \& Archer, 2008; Archer, Adolfsson, \& Karlsson, 2008a; Archer, Adrianson, Plancak, \& Karlsson, 2008b; Garcia, 2011a, 2011b, 2012a, 2012b; Garcia \& Archer, 2012; Garcia, Rosenberg, Erlandsson, \& Siddiqui, 2010; Garcia \& Siddiqui, 2009a, 2009b; Karlsson \& Archer, 2007; Palomo, Beninger, Kostrzewa, \& Archer, 2008a, 2008b; Palomo, Kostrzewa, Beninger, \& Archer, 2007; Zöller \& Archer, 2009; Zöller, Karlsson, \& Archer, 2009; for a recent review see Garcia, Ghiabi, Moradi, Siddiqui, \& Archer, 2012). Several studies have indicated that NA is associated with feelings such as anger, contempt, guilt, shame, fear, anxiety, depressiveness, stress, distress and health complaints whereas PA is linked to enthusiasm, activity, exercise, feelings of duty and control (Watson \& Clark, 1988; Watson, Pennebaker, \& Folger, 1986; Watson, Carey, \& Carey, 1988a; Watson \& Clark, 1988; Watson, Clark, \& Tellegen, 1988b).

Nevertheless, affect can be measured in different dimensions (e.g., high or low activation). The type of dimension might have implications regarding the well established relationship between exercise, affect, and well-being. For instance, Garcia and Erlandssiuon (2011) demonstrated that different dimensions of 
affect predict different association between personality and well-being. Moreover, in the field of Positive Psychology, research on well-being complements measures of physical (e.g. health) and material (e.g. income) well-being with assessments of optimal experience by focusing on people's full engagement and optimal performance in existential challenges of life (i.e., Psychological Well-Being; PWB, Ryan, \& Deci, 2001).

In the present set of studies we aim to investigate the relationship of frequent exercise habits to different dimensions of affect (high and low activity) and health (physical and psychological). We investigate this relationship in the context of individuals' gender, age, psychosomatic symptoms, sleeping problems, smoking habits, and Body Mass Index (BMI). Next we will briefly present the well established relationship between frequent exercise and health, the difference between high and low activation affect, and the notion of psychological resources (i.e., PWB).

\section{Frequent Exercise and Health}

The effect of frequent exercise on health may be illustrated through reference to two domains: substance use and dietary habits linked to overweight. Regular physical activity appears to prevent eventual health-related habits and hazards. Norris and colleagues (1992), for example, showed that regular exercise and physical training induced beneficial effects against psychological stress and increased well-being among participants. In another study (Delisle, Werch, Wong, Bian, \& Weiler, 2010), among 822 adolescents attending a large, diverse suburban school, adolescents who engaged in "vigorous physical activity" expressed lower usage of marijuana, consumed more healthy carbohydrates and fats, used stress management techniques more frequently and reported a higher quality of sleep than adolescents engaged in low "vigorous physical activity" (i.e., those who where more-or-less sedentary). Moreover, Dishman and colleagues (2006) have indicated that that frequent physical activity and sport participation reduced the risk for depression among adolescent girls by positive influences on physical self-concept that operate independently of fitness, Body Mass Index (BMI), and perceptions of sports competence, body fat, and appearance. That is, regular physical activity brings beneficial outcomes including body weight status, as well as self-perception attributes, whereas sedentary behavior and failure to being regularly physical active brings unhealthy outcomes.

\section{Beyond Gender, Age, and Occupation}

In two studies involving work-related stress and personal attributes, Andersson-Arntén and colleagues (2008) showed that NA was predicted by stress, anxiety and work stress; further studies indicated that stress at work induced more anxiety, general psychosomatic symptoms, NA, and depression (Andersson-Arntén, 2009). Interestingly, whereas work-stress was predictive for depression, anxiety, general stress and psychological stress, sexual life satisfaction was counter predictive for all these variables (Andersson-Arntén, 2009). Nevertheless, long working hours, lifestyle and working environment factors are the main predictors of workers' health status (Hurrell \& Maclancy, 1988) and psychological vulnerability (Michelsen \& Bildt, 2003; Nishikitani, Nakao, Karita, \& Tennant, 2001); this situation is complicated by the pressures created by gender and the specter raised by unemployment (Bildt \& Michelsen, 2002, 2003). Moreover, Takada and colleagues (2009) examined the links between lifestyle, working environment, depressive symptoms and suicide ideation in 4118 Japanese business employees (2834 male and 1284 female). They found that the factors associated with depressive symptoms over both genders were: high levels of job stress, drinking problems, insufficient sleep, lack of social support, and absence of stress reduction techniques such as physical exercise.

Indeed, a wide range of self-report studies have shown that regular physical exercise reduces stress symptoms, mood disorder, anxiety and depressiveness (see also Broman-Fulks \& Storey, 2008; Janisse, Nedd, Escamille, \& Nies, 2004; Smith, Blumentha, Babyak, Georgiades, Hinderliter, \& Sherwood, 2007; Tsang, Chan, \& Cheug, 2008; Wang, Bannuru, Ramel, Kupelnick, Scott, \& Schmid, 2010). Experimental approaches point in the same direction. Barnes and colleagues (2010) investigated pre- and post-exercise attentional bias that may modulate reported reductions in negative affect and anxiety. Over consecutive laboratory visits, 30 high trait anxious participants completed $30 \mathrm{~min}$ of exercise on a cycle ergometer at $70 \%$ of their heart rate reserve, or completed a 30-min quiet rest protocol. During each intervention, pre-test and post-test modified dot-probe assessments of attentional bias were completed, as were a series of self-report anxiety and affect questionnaires. They observed that PA and reaction time improved markedly after exercise thereby implying that exercise facilitates attentional scope.

\section{High and Low Activation Affect}

Although most would agree in viewing positive and negative experiences as opposite ends of a continuum, there is much evidence that they are best construed as two separate systems (for a review see MacLeod \& Moore, 2000). In the context of health, this is important because the two systems are also measures of anxiety and depression - anxiety is a state of high NA whereas depression is a mixed state of high NA and low PA (Clark \& Watson, 1991). Moreover, the two systems are almost synonymous with different constructs of personality traits. For instance, extrovert behavior is positively related to high levels of PA and being more reactive to positive stimuli whereas neurotic behavior is positively related to high levels of NA and more reactive to negative stimuli (Larsen \& Ketelaar, 1991).

Watson and Tellegen (1985) have actually presented these as two independent dimensions: high versus low PA and high versus low NA. One of the most used instruments to measure affect is the Positive Affect and Negative Affect Schedule (PANAS by Watson et al., 1988). Rusell and Carroll (1999) point out that the PANAS scales are predominated by high activation items: while some PANAS items (e.g., "interested") may not be common in other scales, other items (e.g., "happy") are not included in the PANAS. Indeed, findings suggest that PANAS items reflect engagement with a stimulus (for a review see Schimmack, 2007).

Hence, the PANAS mainly measures high activation affect while other scales (e.g., the Emotional Well-Being Scale by Diener \& Biswas-Diener, 2008) assess low activation affects. This can be seen in light of the circumplex model first presented by Russell (1980). According to this model the affects included in the PANAS are all located in the northwest and 
northeast segments of the circumplex. In other words, they measure only highly activated PA and NA. This model has two important implications that may be assumed of importance for this study. Firstly, that some emotions are similar to each other yet measurably different than other emotions. Secondly, that the majority of emotional experience can be captured by two dimensions. (Larsen \& Diener, 1992).

\section{Psychological Well-Being}

Ryff (1989) has proposed six constructs as defining positive psychological functioning: 1) positive relations with others; 2) environmental mastery; 3) self-acceptance; 4) autonomy; 5) personal growth; and 6) purpose in life (see Table 1 for a definition of each construct). The six constructs define PWB both theoretically and operationally, and they probably identify what promotes effective adaptation to life events and emotional and physical health (Ryff \& Singer, 1998). The PWB constructs not only promote well-being but also are a measure of well-being. For example, analogous to hunger, autonomy is considered as a need in human nature that has to be satisfied in order to preserve or increase well-being and adaptive behavior (Deci \& Flaste, 1996).

Comparing PWB between young (aged 18 - 29 years), midlife (30 - 64 years), and old (65 years or more) adults, Ryff found that certain aspects of PWB increased or decreased with age, while others did not change at all. Environmental mastery and autonomy increased with age (especially between young to midlife), purpose in life and personal growth decreased (especially between midlife to old), and no differences were found in self-acceptance and positive relations with others.

Recent research has linked PA as a predictor of Psychological Well-Being. Urry and colleagues (2004), for example, investigated whether engaging with goal-directed stimuli contributed to well-being by exploring correlations between individual differences in baseline prefrontal activation and PWB. The results validated the hypothesis and affect, especially high activation PA (e.g., "interested," "strong"), emerged as an important factor in the prediction of PWB (see also Garcia, 2011c, 2012b; Garcia \& Archer, 2012; Garcia \& Siddiqui, 2009b).

In this context, it is important to bear in mind that positive emotions may also broaden people's mindsets and build enduring personal psychological resources (Fredrickson, 2006). For instance, participants in a positive-emotion condition listed significantly more things they would like to do than participants in a negative-emotion condition (Fredrickson \& Branigan, 2005). The effect of broadened thinking may increase the odds of discovering positive meaning in life events (Fredrickson,
2006). In addition, Tugade and Fredrickson (2004) found that a person who reports high activated PA before doing a timepressured speech preparation experiences, alongside high anxiety feelings, higher levels of happiness and interest. Nevertheless, both PA and NA might be adaptive, depending on the social context. From an evolutionary perspective, it is reasonable to assume that negative emotions have grown part of the toolbox of most organic beings. After all, negative emotions probably increase the chances of survival in life-threatening situations because they bring attention to threatening stimuli and facilitate rapid action (Dijksterhuis \& Aarts, 2003). Thus, affectivity may play a role, not only as a measure of well-being, but also as contributor in the promotion of PWB.

\section{The Present Set of Studies}

The health-promoting effects of physical exercise for health and healthy behavior are well documented. It can be observed that high BMI is associated positively with sedentary conditions whereas lower scores of physical activity are associated with high NA. Nonetheless, the positive influences of frequently exercising might go beyond demographical variables such a gender, age, occupation and even BMI. Personal attributes involving affectivity may uncover relationships that either promote or hinder an individual's propensity for physical exercise.

Nonetheless, we suggest that the dimension of affect (high or low activation) needs to be taken into consideration. Furthermore, the relationship between frequent exercise and PWB should complement and expand the effects of frequent exercise on health. We expected frequently exercising being positively predicted by high activation PA and counter-predicted by high activation NA. Moreover, this relationship was expected to remain significant while controlling for gender, age, occupation, and BMI. Both PA and exercise frequency was expected to be negatively related to psychosomatic symptoms, sleeping problems, and smoking. Finally, frequent exercise was also expected to be positively related to PWB.

\section{Study 1: High Activation Affect}

\section{Participants and Procedure}

A total of 635 participants ( 370 females and 265 males) with an age mean of $18.53(S D=5.01)$ from the different settings (lower school, high school, university, white collar and blue collar workers at corporate enterprises, government employees, and state-owned and health establishments) were guaranteed

Table 1.

The six constructs of psychological well-being.

\begin{tabular}{ll}
\hline \multicolumn{1}{c}{ PWB Construct } & $\begin{array}{l}\text { Emphasis on acceptance of self and of one's past life. } \\
\text { Self-acceptance }\end{array}$ \\
$\begin{array}{l}\text { Positive relations with others } \\
\text { of greater love, deeper friendship, and more complete identification with others and warm relating to others. } \\
\text { Expressions of internal locus of evaluation, thus not looking to others for approval but evaluating oneself } \\
\text { by personal standards. }\end{array}$ \\
$\begin{array}{l}\text { The individual's ability to choose or create environments suitable to his or her psychic conditions. } \\
\text { Purpose in life }\end{array}$ & $\begin{array}{l}\text { Having goals, intentions, and a sense of direction, all of which contribute to the feeling that life is meaningful. } \\
\text { Personal growth }\end{array}$ \\
\hline
\end{tabular}


complete anonymity and assured that their collaboration was on a voluntary basis. First, the participants completed the background and health questionnaire that provided information regarding age, gender, education, etc, but particularly propensity for regular physical exercise. Second, they completed the instrument that measures affect.

\section{Instruments}

Background and Health questionnaire (Karlsson \& Archer, 2007). This instrument was applied to collect background data providing health and health-related information about each participant. The questionnaire consists of items pertaining to age, gender and education, occupation, as well as propensity to perform regular physical exercise, smoking habits, and sleeping problems.

The Positive Affect and Negative Affect Schedule (PANAS; Watson et al., 1988). The PANAS was used to measure high activation affect. Participants are instructed to rate to what extent they generally have experienced 20 different feelings or emotions (10 PA and 10 NA) for the last weeks, using a 5-point Likert scale $(1=$ very slightly, $5=$ extremely $)$. The Swedish version of the PANAS used in the present study has been used in many other studies (e.g., Archer et al., 2008b; Garcia \& Moradi, 2011; Palomo et al., 2007). The 10-item PA scale includes adjectives such as strong, proud, and interested (Cronbach's $\alpha$ $=.80$ ). The 10-item NA scale includes adjectives such as afraid, ashamed, and nervous (Cronbach's $\alpha=.75$ ).

\section{Results and Discussion}

A Correlation analysis was conducted in order to establish the relationship among the variables in the study. As Table 2 shows, affect was significantly related to smoking, sleeping problems, and exercise frequency. Specifically, PA was negatively related to the number of cigarettes a participant smoked on a weekly basis and to how often the participant had problems falling asleep. In contrast, PA was positively related to exercise frequency. For NA the relationships were inversed.

A partial correlation analysis was conducted in order to investigate if the relationship between affect and exercise frequency remained significant beyond demographical variables. We controlled this relationship for gender, age, and occupation. As shown in Table 3, affect was strongly related to exercise frequency in the same manner as depicted above.

A Multiple Regression Analysis (MRA) was conducted in order to investigate the relationship between affect and exercise frequency further. Affect was used as the independent variable and exercise frequency was used as the dependent variable in the equation. Besides affect, gender and age was used as predictor of frequently exercising. Both PA and NA predicted how
Table 2.

Correlations among variables in Study $1(\mathrm{~N}=635)$.

\begin{tabular}{lccccccc}
\hline & 1 & 2 & 3 & 4 & 5 & 6 & 7 \\
\hline 1) Positive affect & - & & & & & & \\
2) Negative affect & -.08 & - & & & & & \\
3) Age & .05 & -.02 & - & & & & \\
4) Smoking & $-.15^{*}$ & .09 & -.08 & - & & \\
5) Psychosomatic & .04 & .03 & .04 & $.29^{* * *}$ & - & & \\
$\quad$ symptoms & $-.43^{* * *}$ & $.43^{* * *}$ & -.01 & .09 & -.04 & - & \\
6) Sleeping problems & -.04 & & & & \\
7) Exercise frequency & $.44^{* * *}$ & $-.18^{* * *}$ & .01 & -.02 & .01 & $-.39^{* * *}$ & - \\
\hline
\end{tabular}

Note: ${ }^{*} p<.05 ;{ }^{* * *} p<.001$.

Table 3.

Partial correlations between exercise frequency and affect controlling for gender, age, and occupation $(\mathrm{N}=635)$.

\begin{tabular}{lccc}
\hline & 1 & 2 & 3 \\
\hline 1) Exercise Frequency & - & & \\
2) Positive Affect & $.44^{* * *}$ & - & \\
3) Negative Affect & $-.23^{* * *}$ & -.089 & - \\
\hline Note: ${ }^{* * *} p<.001$. & & &
\end{tabular}

often participants reported they were physical active (see Table 4).

As expected, frequently exercising is related to high activation affect beyond demographical variables such as gender, age, and occupation. The next study aims to replicate the results presented here and investigate if the high activation affectivity-frequent exercise relationship is independent of BMI as well. Study 2 was conducted among adolescents due to the close relation between BMI, self-image, and self-esteem during this period of life.

\section{Study 2: High Activation Affect and BMI}

\section{Participants and Procedure}

A total of 311 participants (183 boys and 128 girls) were assigned to study 2 . This sample included lower school pupils ( $n$ $=84$, aged $13-15$ years $)$, high school pupils $(n=133$, aged $16-$ 18 years), and university students $(n=94$, aged $19-29$ years $)$. All residents in Kungsbacka, Sweden. As in Study 1, participants were guaranteed complete anonymity and assured that their collaboration was on a voluntary basis. First, the participants completed the background and health questionnaire. In the background questionnaire we included the measures to calculate BMI. The PANAS was distributed last.

Table 4.

Results of the MRA using gender, age, PA and NA as predictors of exercise frequency $(\mathrm{N}=635)$.

\begin{tabular}{ccccccccc}
\hline Predictor Variable & Outcome Variable & Adj $R^{2}$ & Unst. B & Unst. SE & Stand. $\beta$ & $F$ & $t$ & $p$ \\
\hline Gender (G) & & - & .27 & .11 & .10 & - & 2.46 & $<.05$ \\
Age (A) & & - & -.01 & .01 & -.01 & - & -.22 & .82 \\
Positive Affect (PA) & Exercise frequency & - & .69 & .07 & .42 & - & 10.28 & $<.001$ \\
Negative Affect (NA) & & - & -.35 & .07 & -.20 & - & -4.71 & $<.001$ \\
G, A, PA, NA & & .23 & - & - & - & 35.07 & - \\
\hline
\end{tabular}




\section{Instruments}

Background and Health questionnaire (Karlsson \& Archer, 2007). We used the same questionnaire from Study 1 consisting of items pertaining to age, gender and education, as well as propensity to perform regular physical exercise, and sleeping problems.

Body Mass Index (BMI). The body mass index, or Quetelet index, is a heuristic measure of body weight based on a person's weight and height. Although BMI does not actually measure the percentage of body fat, it is used to estimate a healthy body weight based on a person's height, and with the assumption of an average body composition. Body mass index is defined as the individual's body weight divided by the square of his or her height. Participants were simply asked to report their weight and height.

The Positive Affect and Negative Affect Schedule (PANAS; Watson et al., 1988). The PANAS was again used to measure high activation affect. Reliability was good for both PA (Cronbach's $\alpha=.79$ ) and NA (Cronbach's $\alpha=.82$ ).

\section{Results and Discussion}

High activation affect was again significantly related to sleeping problems, and exercise frequency (see Table 5). As in Study 1, while NA was positively related to how often adolescents had problems falling asleep, PA was negatively related. However, only PA was positively related to frequent physical activity. On the other hand, NA was positively related to psychosomatic symptoms and sleeping problems. It is word to notice that BMI was negatively related to exercise frequency. That is, adolescents who often engage in physical activities had lower BMI.

We controlled the high activation affect-exercise frequency relationship for gender, age, and BMI. As shown in Table 6, PA was still positively correlated to exercise frequency in the same manner as depicted above.

Table 5.

Correlations among variables in Study $2(\mathrm{~N}=311)$.

\begin{tabular}{lccccccc}
\hline & 1 & 2 & 3 & 4 & 5 & 6 & 7 \\
\hline 1) Positive affect & - & & & & & & \\
2) Negative affect & -.10 & - & & & & & \\
3) Age & -.05 & -.08 & - & & & & \\
4) Psychosomatic & -.08 & $.27^{* * *}$ & .02 & - & & & \\
$\quad$ symptoms & & & & & & & \\
5) Sleeping problems & $-.26^{* * *}$ & $.25^{* * *}$ & .07 & $.31^{* * *}$ & - & & \\
6) Exercise frequency & $.24^{* * *}$ & -.08 & -.01 & -.02 & $-.12^{*}$ & - & - \\
7) BMI & .01 & -.01 & $.18^{*}$ & .07 & .10 & $-.16^{*}$ & - \\
\hline
\end{tabular}

Note: ${ }^{*} p<.05 ;{ }^{* * *} p<.001$

Table 6.

Partial correlations between exercise frequency and affect controlling for gender, age, and BMI $(\mathrm{N}=311)$.

\begin{tabular}{lccc}
\hline & 1 & 2 & 3 \\
\hline 1) Exercise frequency & - & & \\
2) Positive affect & $.27^{* * *}$ & - & - \\
3) Negative affect & -.07 & -.08 & \\
\hline Note: ${ }^{* * *} p<.001$. & & &
\end{tabular}

As expected, the high activation affect-frequent exercise relationship is independent of BMI as well as gender and age. Hence, the positive effect of frequently exercising goes beyond such demographic variables. In Study 3 we aim to replicate the results presented to this point and also to expand the investigation in regard to the positive effect of frequent exercise and health by measuring PWB among adolescents.

\section{Study 3: High Activation Affect and PWB}

\section{Participants and Procedure}

Participants were pupils at two high schools in the county of Blekinge, Sweden. The total of the participants was 135 (70 boys and 65 girls) with an age mean of 17.00 years $(S D=.88)$. All participants were guaranteed complete anonymity and assured that their collaboration was on a voluntary basis. All completed the background and health questionnaire (same as in Study 1 and 2), the PANAS, and the PWB measure.

\section{Instruments}

Background and Health questionnaire (Karlsson \& Archer, 2007). We used the same questionnaire from Study 1 and 2 consisting of items pertaining to age, gender and education, as well as propensity to perform regular physical exercise, and sleeping problems.

The Positive Affect and Negative Affect Schedule (PANAS; Watson et al., 1988). The PANAS was again used to measure high activation affect. Reliability was good for both PA (Cronbach's $\alpha=.84$ ) and NA (Cronbach's $\alpha=.82$ ).

Ryff's Short Measurement of Psychological Well-Being (Clarke, Marshall, Ryff, \& Wheaton, 2001). PWB was operationalized with Ryff's own short version (18 items, 3 for each construct). The six constructs are: 1) autonomy (e.g., "I have confidence in my own opinions, even if they are contrary to the general consensus"); 2) environmental mastery (e.g., " I am quite good at managing the responsibilities of my daily life"); 3 ) self-acceptance (e.g., "I like most aspects of my personality"); 4) purpose in life ("Some people wander aimlessly through life, but I am not one of them"); 5) personal growth (e.g., "For me, life has been a continuous process of learning, changing, and growth") and 6) positive relations with others (e.g., "People would describe me as a giving person, willing to share my time with others").

The Swedish version has been used in previously published studies (e.g., Garcia, 2011c; Garcia, 2012b; Garcia \& Siddiqui, 2009 b). For this study we simply summarized all the 18 items to form a PWB score (Cronbach's $\alpha=.78$ ).

\section{Results and Discussion}

Affect was again significantly related to psychosomatic symptoms, sleeping problems, and exercise frequency. Moreover, PA was positively related to PWB. NA, in contrast, was negatively related to PWB. PWB was also positively related to frequent exercise and negatively related to psychosomatic symptoms and sleeping problems. In other words, the more adolescents scored in the six PWB constructs, the more they reported exercising in a frequent basis and the less they reported pain in shoulders, head and having sleeping problems (see Table 7).

A MRA was conducted in order to investigate the relation- 
ship between PWB and exercise frequency further. All six PWB constructs were used as the independent variables and exercise frequency was used as the dependent variable in the equation. Although the whole PWB scale was related to frequently exercising, only the construct of self-acceptance was a significant predictor of routinely engaging in physical activities (see Table 8). This specific finding is in concordance with the finding from Study 2 in regard to BMI. It is tentatively to suggest that as long as there is acceptance of the self, the adolescent is able to perform healthy behaviors.

The last study was conducted among adults in order to replicate the findings in regard to PWB and to investigate if frequent exercise is related to low activation affect.

\section{Study 4: Low Activation Affectivity and PWB Participants and Procedure}

A total of 150 white collar workers ( 90 females and 60 males) with an age mean of $43.07(S D=12.68)$ were asked to complete the background and health questionnaire, the affect measure, and the PWB measure. Participants were guaranteed complete anonymity and assured that their collaboration was on a voluntary basis.

\section{Instruments}

Background and Health questionnaire (Karlsson \& Archer, 2007). We used the same questionnaire from Study 1-3.

Emotional Well-Being Scale (EWS; Diener \& Biswas-Diener, 2008). The EWS was used in order to measure low activation affect. The EWS consist of 16 items, eight of which measure PA (e.g., pleasant, contented) and the other eight measure NA (e.g., unpleasant, sad). The EWS went through the formal process of translation and backtranslation. Although this is the first time the EWS is used in a Swedish sample, the EWS showed proper reliability for both PA (Cronbach's $\alpha=.83$ ) and NA (Cronbach's $\alpha=.84)$.

Ryff's Short Measurement of Psychological Well-Being (Clarke et al., 2001). Ryff's own short version was again used to measure PWB. Again, we simply summarized all the 18 items to form a PWB score (Cronbach's $\alpha=.75$ ).

\section{Results and Discussion}

In contrast to Study 1-3, affect was not significantly related to frequently exercising. However, as in Study 1-3, affect was related to sleeping problems and psychosomatic symptoms. Specifically, PA was related to less pain and sleeping problem, NA was related to more pain and regularly experiencing sleep- ing problems. It is important to point out that, equal to findings in Study 3, PWB was still related to both affect and exercise frequency. In other words, while PWB might be promoted by both affect dimensions, only approach related or high activation affect (e.g., engaged, interested), rather than low activation affect (e.g., contented, pleasant), might promote frequently exercising (see Table 9).

\section{General Discussion}

Taken together, the results from the four studies indicate that high activation affect and PWB predict the propensity to regularly physical activity. More specifically, high activation PA and PWB predicted frequent engagement in regular exercise habits. Frequent exercise, frequent experiencing PA, and psychological resources such self-acceptance predict less smoking, less sleeping, and less psychosomatic symptoms.

Moreover, the positive relationship of the variables in this triad (i.e., high activation PA, frequent exercise, and PWB) goes beyond demographic variables such as gender, age, and occupation. At least among adolescents this is true despite even BMI. Perhaps because self-acceptant behavior leads to approach related affect. Nevertheless, we suggest that the results of these four studies should be seen as a circle of exercise-approach behavior (see Figure 1). That is, while it is true that experiencing engagement and enthusiasm, for example, might broaden people's mindsets and build enduring personal psychological resources (Fredrickson, 2006), such as personal growth, the opposite might be true as well: frequent exercise might lead to concepts of the self that emphasise continued growth and the confronting of new challenges, such self-concept, in turn, leading to both high (e.g., proud) and low active-

Table 7.

Correlations among variables in Study $3(\mathrm{~N}=135)$.

\begin{tabular}{lccccccc}
\hline & 1 & 2 & 3 & 4 & 5 & 6 & 7 \\
\hline (1) Positive affect & - & & & & & \\
(2) Negative affect & -.05 & - & & & & \\
(3) Age & .13 & -.01 & - & & & \\
$\begin{array}{l}\text { (4) Psychosomatic } \\
\quad \text { symptoms }\end{array}$ & -.15 & $.27^{* *}$ & .06 & - & & \\
$\begin{array}{l}\text { (5) Sleeping } \\
\text { problems }\end{array}$ & $-.23^{* *}$ & $.38^{* * *}$ & .02 & $.44^{* * *}$ & - & \\
(6) Exercise frequency & $.27^{* *}$ & -.05 & .06 & -.10 & $-.23^{* *}$ & - \\
(7) PWB & $.51^{* * *}$ & $-.44^{* * *}$ & .11 & $-.18^{*}$ & $-.28^{* * *}$ & $.25^{* *}$ & - \\
\hline
\end{tabular}

Note: ${ }^{*} p<.05 ;{ }^{* *} p<.01 ;{ }^{* * *} p<.001$.

Table 8.

Results of the MRA using all six PWB constructs as predictors of exercise frequency $(\mathrm{N}=135)$.

\begin{tabular}{ccccccccc}
\hline Predictor Variable & Outcome Variable & Adj $R^{2}$ & Unst. B & Unst. SE & Stand. $\beta$ & $F$ & $t$ & $p$ \\
\hline Self-Acceptance & & - & .06 & .03 & .24 & - & 2.02 & $<.05$ \\
Positive relations with others & & - & .03 & .03 & .09 & - & .87 & .39 \\
Autonomy & & - & .03 & .03 & .07 & - & -.83 & .41 \\
Environmental Mastery & Exercise frequency & - & -.01 & .03 & -.01 & - & -.09 & .93 \\
Purpose in life & & - & .04 & .03 & .13 & - & 1.39 & .17 \\
Personal growth & & - & -.05 & .03 & -.15 & - & -1.60 & .11 \\
PWB & & .11 & - & - & - & 2.53 & - & $<.05$ \\
\hline
\end{tabular}


Table 9.

Correlations among variables in Study $4(\mathrm{~N}=150)$.

\begin{tabular}{|c|c|c|c|c|c|c|c|c|}
\hline & 1 & 2 & 3 & 4 & 5 & 6 & 7 & 8 \\
\hline (1) Positive affect & - & & & & & & & \\
\hline (2) Negative affect & $-.49^{* * *}$ & - & & & & & & \\
\hline (3) Age & -.02 & .04 & - & & & & & \\
\hline (4) Smoking & .03 & -.14 & $.20^{*}$ & - & & & & \\
\hline $\begin{array}{l}\text { (5) Psychosomatic } \\
\text { symptoms }\end{array}$ & $-.23^{*}$ & $.30^{* * *}$ & -.13 & -.01 & - & & & \\
\hline $\begin{array}{l}\text { (6) Sleeping } \\
\text { problems }\end{array}$ & $-.25^{* *}$ & $.44^{* * *}$ & .03 & -.06 & $.23^{*}$ & - & & \\
\hline $\begin{array}{l}\text { (7) Exercise } \\
\text { frequency }\end{array}$ & .08 & -.11 & -.17 & $-.27^{* *}$ & -.06 & -.02 & - & \\
\hline (8) PWB & $.51^{* * *}$ & $-.50^{* * *}$ & -.15 & -.10 & -.11 & -.19 & $.22^{*}$ & - \\
\hline
\end{tabular}

Note: ${ }^{*} p<.05 ;{ }^{* *} p<.01 ;{ }^{* * *} p<.001$.
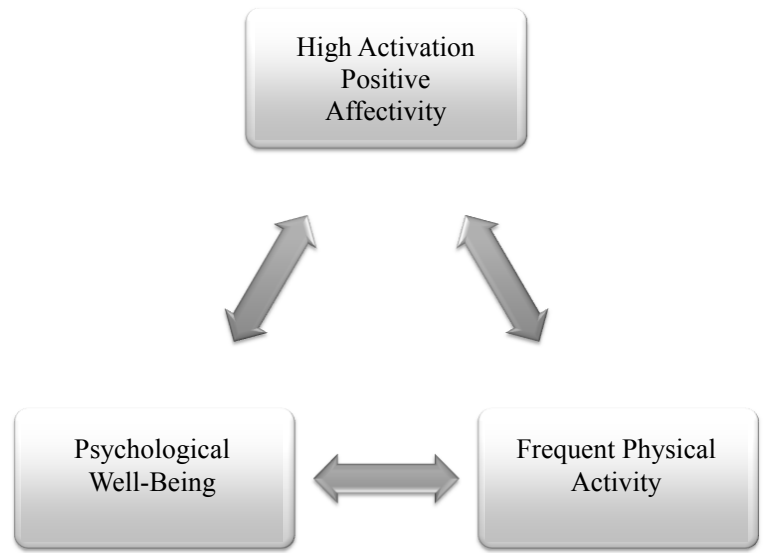

Figure 1.

The circle of exercise-approach behaviour.

tion PA (e.g., contentedness). Our suggestions can be seen in light of recent research that suggest that, among adolescent girls, intention and perceived behavioral control predicted changes in physical activity and physical activity predicted changes in intention, affective attitude, and perceived behavioral control (Raudsepp et al., 2010). We suggest that the promotion of selfacceptance and high activated PA might be necessary in order to create frequent exercise habits.

"Being entirely honest with oneself is a good exercise" Sigmund Freud.

\section{Acknowledgements}

We would like to direct our gratitude to The Swedish National Centre for Research in Sports (CIF) for supporting this project (Grant nr. P2012-0097). We would also like to thank Anders Welin, Nariman Hakiminejad, Patricia Rosenberg, and Erik Lindskär for their assistance with the data. All authors are indebted to the participants for their help in facilitating the study and to the reviewers who helped improve the original manuscript.

\section{REFERENCES}

Andersson-Arntén, A. C. (2009). Partnership relation quality modu- lates the effects of work-stress on health. Doctoral Dissertation, Gothenburg: Department of Psychology, University of Gothenburg.

Andersson-Arntén, A. C., Jansson, B., \& Archer, T. (2008). Influence of affective personality type and gender upon coping behavior, mood and stress. Individual Differences Research, 6, 139-168.

Annesi, J. J. (2010). Relations of changes in self-regulatory efficacy and physical self-concept with improvements in body satisfaction in obese women initiating exercise with cognitive-behavioral support. Body Image, 7, 356-359. doi:10.1016/j.bodyim.2010.05.001

Archer, T., Adolfsson, B., \& Karlsson, E. (2008). Affective personality as cognitive-emotional presymptom profiles regulatory for self-reported health predispositions. Neurotoxicity Research, 14, 1-25. doi:10.1007/BF03033573

Archer, T., Adrianson, L., Plancak, A., \& Karlsson, E. (2007). Influence of affective personality on cognition-mediated emotional processing: need for empowerment. European Journal of Psychiatry, 21, 248-262. doi:10.4321/S0213-61632007000400002

Arciero, P. J., \& Ormsbee, M. J. (2009). Relationship of blood pressure, behavioral mood state, and physical activity following caffeine ingestion in younger and older women. Applied Physiology, Nutrition and Metabolism, 34, 754-762. doi:10.1139/H09-068

Baldwin, R. C. (2010). Preventing late-life depression: A clinical update. International Psychogeriatrics, 1, 1-9.

Barnes, R. T., Coombes, S. A., Armstrong, N. B., Higgins, T. J., \& Janelle, C. M. (2010). Evaluating attentional and affective changes following an acute exercise bout using a modified dot-probe protocol. Journal of Sports Sciences, 28, 1065-1076. doi:10.1080/02640414.2010.489196

Bildt, C., \& Michélsen, H. (2002). Gender differences in the effects from working conditions on mental health: A 4-year follow-up. International Archives of Occupational and Environmental Health, 75, 252-258.

Bildt, C., \& Michélsen, H. (2003). Occupational conditions exceed the importance of non-occupational conditions and ill health in explaining future unemployment among women and men. Archives of Women's Mental Health, 6, 115-126. doi:10.1007/s00737-002-0177-8

Broman-Fulks, J. J., \& Storey, K. M. (2008). Evaluation of a brief aerobic exercise intervention for high anxiety sensitivity. Anxiety, Stress and Coping, 21, 117-128. doi:10.1080/10615800701762675

Clarke, P. J., Marshall, V. M., Ryff, C. D., \& Wheaton, B. (2001). Measuring psychological well-being in the Canadian study of health and aging. International Psychogeriatrics, 13, 79-90. doi:10.1017/S1041610202008013

Clark, C. L., \& Watson, D. (1991). Tripartite model of anxiety and depression: Psychometric evidence and taxonomic implications. Journal of Abnormal Psychology, 100, 316-336. doi: 10.1037/0021-843X.100.3.316

Deci, E. L., \& Flaste, R. (1996). Why we do what we do: Understanding self-motivation. London: Penguin Books.

Delisle, T. T., Werch, C. E., Wong, A. H., Bian, H., \& Weiler, R. (2010). Relationship between frequency and intensity of physical activity and health behaviors of adolescents. Journal of School Health, 80, 134-140. doi:10.1111/j.1746-1561.2009.00477.x

Diener, E., \& Biswas-Diener, R. (2008). Happiness: Unlocking the mysteries of psychological wealth. Malden, MA: Blackwell Publishing.

Dishman, R. K., Hales, D. P., Pfeiffer, K. A., Felton, G. A., Saunders, R., Ward, D. S., Dowda, M., \& Pate, R. R. (2006). Physical selfconcept and self-esteem mediate cross-sectional relations of physical activity and sport participation with depression symptoms among adolescent girls. Health Psychology, 25, 396-407. doi:10.1037/0278-6133.25.3.396

Dijksterhuis, A., \& Aarts, H. (2003). On wildebeests and humans: The preferential detection of negative stimuli. Psychological Science, 14, 14-18. doi:10.1111/1467-9280.t01-1-01412

Fredrickson, B. L. (2006). The broaden-and-build theory of positive emotions. In M. Csikszentmihalyi, \& I. S. Csikszentmihalyi (Eds), A life worth living: Contributions to positive psychology (pp. 85-103). New York: Oxford University Press.

Fredrickson, B. L., \& Branigan, C. (2005). Positive emotions broaden 
the scope of attention and thought-action repertoires. Cognition and Emotion, 19, 313-332. doi:10.1080/02699930441000238

Garcia, D. (2011a). Adolescents' happiness: The role of the affective temperament model on memory and apprehension of events, subjective well-being, and psychological well-being. Doctoral Dissertation, Gothenburg: Department of Psychology, University of Gothenburg.

Garcia, D. (2011b). The affective temperaments: Differences between adolescents in the big five model and cloninger's psychobiological model of personality. Journal of Happiness Studies. doi:10.1007/s10902-011-9303-5

Garcia, D. (2011c). Two models of personality and well-being among adolescents. Personality and Individual Differences, 50, 1208-1212. doi:10.1016/j.paid.2011.02.009

Garcia, D. (2012a). Interpretation and recognition for words in a short story (IRWSS) [Database record]. American Psychological Association's PsycTESTSTM.

Garcia, D. (2012b). The affective temperaments and self-acceptance: adolescents' life satisfaction and psychological well-being. In M. Vassar (Ed.), The psychology of life satisfaction. New York: Nova Science Publishers.

Garcia, D., \& Archer, T. (2012). Adolescent life satisfaction and well-being. Journal of Alternative Medicine Research. In press.

Garcia, D., \& Erlandsson, A. (2011). The relationship between personality and subjective well-being: Different association patterns when measuring the affective component in frequency and intensity. Journal of Happiness Studies, 12, 1023-1034. doi:10.1007/s10902-010-9242-6

Garcia, D., Ghiabi, B., Moradi, S., Siddiqui, A., \& Archer, T. (2012). The happy personality: A tale of two philosophies. In N. G.-C. Vassar (Ed.), Psychology of personality. New York: Nova Science Publishers.

Garcia, D., \& Moradi, S. (2011). Adolescents' temperament and character: A longitudinal study on happiness. Journal of Happiness Studies. doi:10.1007/s10902-011-9303-5

Garcia, D., Rosenberg, P., Erlandsson, A., \& Siddiqui, A. (2010). On lions and adolescents: Affective temperaments and the influence of negative stimuli on memory. Journal of Happiness Studies, 11, 477-495. doi:10.1007/s10902-009-9153-6

Garcia, D., \& Siddiqui, A. (2009a). Adolescents' affective temperaments: Life satisfaction, interpretation and memory of events. The Journal of Positive Psychology, 4, 155-167. doi: $10.1080 / 17439760802399349$

Garcia, D., \& Siddiqui, A. (2009b). Adolescents' psychological wellbeing and memory for life events: Influences on life satisfaction with respect to temperamental dispositions. Journal of Happiness Studies, 10, 387-503. doi:10.1007/s10902-008-9096-3

Hurrell, J. J., \& Maclancy, M. A. (1988). Exposure to job stress: A new psychometric instrument. Scandinavian Journal of Work, Environment and Health, 14, 27-28.

Janisse, H. C., Nedd, D., Escamille, S., \& Nies, M. A. (2004). Physical activity, social support, and family structure as determinants of mood among European-American and African-American women. Women's Health, 39, 101-116. doi:10.1300/J013v39n01_06

Karlsson, E., \& Archer, T. (2007). Relationship between personality characteristics and affect: Gender and affective personality. Individual Differences Research, 5, 44-58.

Kurth, T., Moore, S. C., Gaziano, J. M., Kase, C. S., Stampfer, M. J., Berger, K., \& Buring, J. E. (2006). Healthy lifestyle and the risk of stroke in women. Archives of Internal Medicine, 166, 1403-1409. doi:10.1001/archinte.166.13.1403

Larsen, R. J., \& Diener, E. (1992). Promises and problems with the circumplex model of emotion. In M. S. Clark (Ed.), Emotion: Review of personality and social psychology (pp. 25-59). Newbury Park, CA: Sage.

Larsen, R. J., \& Ketelaar, T. (1991). Personality and susceptibility to positive and negative emotional states. Journal of Personality and Social Psychology, 61, 132-140. doi:10.1037/0022-3514.61.1.132

MacLeod, A., \& Moore, R. (2000). Positive thinking revised: Positive cognitions, well-being and mental health. Clinical Psychology and Psychotherapy, 7, 1-10.
doi:10.1002/(SICI)1099-0879(200002)7:1<1::AID-CPP228>3.0.CO; $\underline{2-\mathrm{S}}$

Michelsen, H., \& Bildt, C. (2003). Psychosocial conditions on and off the job and psychological illhealth: Depressive symptoms, impaired psychological wellbeing, heavy consumption of alcohol. Occupational Environmental Medicine, 60, 489-496. doi:10.1136/oem.60.7.489

Morris, M., \& Schoo, A. (2004). Optimizing exercise and physical activity in older adults. Edinburgh: Butterworth Heinemann.

Nishikitani, M., Nakao, M., Karita, K., Nomura, K., \& Yano, E. (2005). Influence of overtime work, sleep duration, and perceived job characteristics on the physical and mental status of software engineers. Industrial Health, 43, 623-629. doi:10.2486/indhealth.43.623

Norlander, T., Bood, S. Å., \& Archer, T. (2002). Performance during stress: Affective personality, age and regularity of physical exercise. Social Behavior and Personality, 30, 495-508. doi:10.2224/sbp.2002.30.5.495

Norris, R., Carroll, D., \& Cochrane, R. (1992). The effects of physical activity and exercise training on psychological stress and well-being in an adolescent population. Journal of Psychosomatic Research, 36, 55-65. doi:10.1016/0022-3999(92)90114-H

Palomo, T., Beninger, R. J., Kostrzewa, R. M., \& Archer, T. (2008a). Focusing on symptoms rather than diagnoses in brain dysfunction: Conscious and nonconscious expression in impulsiveness and decision-making. Neurotoxicity Research, 14, 1-20. doi:10.1007/BF03033572

Palomo, T., Beninger, R. J., Kostrzewa, R. M., \& Archer, T. (2008b). Affective status in relation to impulsiveness, motor and motivational symptoms: Personality, development and physical exercise. Neurotoxicity Research, 14, 151-168. doi:10.1007/BF03033807

Palomo, T., Kostrzewa, R. M., Beninger, R. J., \& Archer, T. (2007). Treatment consideration and manifest complexity in comorbid neuropsychiatric disorders. Neurotoxicity Research, 12, 43-60. doi:10.1007/BF03033900

Raudsepp, L., Viira, R., \& Hannus, A. (2010). Prediction of physical activity intention and behavior in a longitudinal sample of adolescent girls. Perceptual and Motor Skills, 110, 3-18. doi:10.2466/pms.110.1.3-18

Rees, D. I., \& Sabia, J. J. (2010). Exercise and adolescent mental health: New evidence from longitudinal data. The Journal of Mental Health Policy and Economics, 13, 13-25.

Rothon, C., Edwards, P., Bhui, K., Viner, R. M., Taylor, S., \& Stansfeld, S. A. (2010). Physical activity and depressive symptoms in adolescents: A prospective study. BMC Medicine, 8, 32. doi: 10.1186/1741-7015-8-32

Russell, J. A. (1980). A circumplex model of affect. Journal of Personality and Social Psychology, 39, 1161-1178. doi:10.1037/h0077714

Rusell, J. A., \& Carroll, J. M. (1999). On the bipolarity of positive and negative affect. Psychological Bulletin, 125, 3-30. doi: $10.1037 / 0033-2909.125 .1 .3$

Ryan, R. M., \& Deci, E. L. (2001). On happiness and human potentials: A review of research on hedonic and eudaimonic well-being. Annual Review of Psychology, 52, 141-166. doi:10.1146/annurev.psych.52.1.141

Ryff, C. D. (1989). Happiness is everything, or is it? Explorations on the meaning of psychological well-being. Journal of Personality and Social Psychology, 57, 1069-1081. doi:10.1037/0022-3514.57.6.1069

Ryff, C. D., \& Singer, B. (1998). The contours of positive human health. Psychological Inquiry, 9, 2-28. doi:10.1207/s15327965pli0901 1

Schimmack, U. (2007). Methodological issues in the assessment of the affective component of subjective well-being. In A. D. Ong, \& M. H. M. Van Dulmen (Eds.), Oxford handbook of methods in positive psychology (pp. 96-110). New York: Oxford University Press.

Sjögren, T., Nissinen, K. J., Järvenpää, S. K., Ojanen, M. T., Vanharanta, H., \& Mälkiä, E. A. (2006). Effects of a physical exercise intervention on subjective physical well-being, psychosocial functioning and general well-being among office workers: A cluster randomized-controlled cross-over design. Scandinavian Journal of Medicine and Science in Sports, 16, 381-390.

doi:10.1111/j.1600-0838.2005.00516.x 
Smith, P. J., Blumenthal, J. A., Babyak, M. A., Georgiades, A., Hinderliter, A., \& Sherwood, A. (2007). Effects of exercise and weight loss on depressive symptoms among men and women with hypertension. Journal of Psychosomatic Research, 63, 463-469. doi:10.1016/j.jpsychores.2007.05.011

Takada, M., Suzuki, A., Shima, S., Inoue, K., Kazukawa, S., \& Hojoh, M. (2009). Associations between lifestyle factors, working environment, depressive symptoms and suicidal ideation: A large-scale study in Japan. Industrial Health, 47, 649-655. doi:10.2486/indhealth.47.649

Tennant, C. (2001). Work-related stress and depressive disorders. Journal of Psychosomatic Research, 51, 697-704.

doi:10.1016/S0022-3999(01)00255-0

Tugade, M. M., \& Fredrickson, B. L. (2004). Resilient individuals use positive emotions to bounce back from negative emotional activation. Journal of Personality and Social Psychology, 86, 320-333. doi:10.1037/0022-3514.86.2.320

Tsang, H. W., Chan, E. P., \& Cheung, W. M. (2008). Effects of mindful and non-mindful exercises on people with depression: A systematic review. British Journal of Clinical Psychology, 47, 303-322. doi:10.1348/014466508X279260

Urry, H. L., Nitschke, J. B., Dolski, I., Jackson, D. C., Dalton, K. M., Mueller, C. J., Rosenkranz, M. A., Ryff, C. D., Singer, B. H., \& Davidson, R. J. (2004). Making life worth living: Neural correlates of well-being. Psychological Science, 15, 367-372. doi:10.1111/j.0956-7976.2004.00686.x

Von Thiele Schwarz, U., Lindfors, P., \& Lundberg, U. (2008). Health-related effects of worksite interventions involving physical exercise and reduced workhours. Scandinavian Journal of Work, En- vironment and Health, 34, 179-188. doi:10.5271/sjweh.1227

Wang, C., Bannuru, R., Ramel, J., Kupelnick, B., Scott, T., \& Schmid, C. H. (2010). Tai chi and psychological well-being: Systematic review and meta-analysis. BMC Complementary and Alternative Medicine, 10, 23-39. doi:10.1186/1472-6882-10-23

Watson, D., \& Clark, L. (1988). Positive and negative affectivity and the relation to anxiety and depressive disorders. Journal of Abnormal Psychology, 97, 346-353. doi:10.1037/0021-843X.97.3.346

Watson, D., \& Tellegen, A. (1985). Toward a consensual structure of mood. Psychological Bulletin, 98, 219-235.

doi:10.1037/0033-2909.98.2.219

Watson, D., Pennebaker, J. W., \& Folger, R. (1986). Beyond negative affectivity: Measuring stress and satisfaction in the workplace. Journal of Organizational Behavior Management, 8, 141-157. doi:10.1300/J075v08n02 09

Watson, D., Carey, L. A., \& Carey, G. (1988a). Positive and negative affectivity and their relation to anxiety and depressive disorders. Journal of Abnormal Psychology, 97, 346-353. doi:10.1037/0021-843X.97.3.346

Watson, D., Clark, L., \& Tellegen, A. (1988b). Development and validation of brief measures of positive and negative affect: The PANAS scales. Journal of Personality and Social Psychology, 54, 1063-1070. doi:10.1037/0022-3514.54.6.1063

Zöller, M. E., \& Archer, T. (2009). Predicting stress in male and female psychiatric patients and healthy volunteers. Social Behavior and Personality, 37, 1081-1094. doi:10.2224/sbp.2009.37.8.1081

Zöller, M. E., Karlsson, E., \& Archer, T. (2009). Self-rated affect among adults presenting psychiatric diagnosis. Individual Differences Research, 7, 14-28. 